\title{
Os Mecanismos do Estado para o Desenvolvimento da Atividade Pesqueira na Baia de Guanabara
}

Felippe Andrade Rainha Geógrafo / Bolsista TCT - FAPERJ da UERJ/FFP - trovadorffp@gmail.com

\section{Resumo}

Venho, neste trabalho, tentar tratar de um importante papel que o Estado possui em nossa sociedade, ou seja, na formulação de políticas públicas principalmente no que se refere às classes menos favorecidas pelo atual sistema, o qual visa à lógica da acumulação em larga escala.

As políticas públicas surgem, atualmente, como mecanismos de auxílio aos grupos sociais a quem elas se dirigem, para que os mesmos obtenham e garantam seus direitos constitucionais que lhes são legalmente assegurados.

É extremamente notório que é de competência do Estado elaborar e realizar medidas que promovam condições plenas e eficazes para a manutenção do comum funcionamento de uma sociedade justa nas suas diversas relações cotidianas. Dessa forma, é o Estado social que terá de promover tais medidas, as quais podemos chamar de políticas públicas.

Com isso, serão apresentados alguns resultados obtidos com a pesquisa e apresentados em meu estudo monográfico de final de curso na Faculdade de Formação de Professores da Universidade Estadual do Rio de Janeiro.

\section{Introdução}

O setor pesqueiro brasileiro, até o início do ano de 2003, sofria com uma série de problemas, os quais faziam da referida atividade, uma prática arriscada (do ponto de vista de obtenção de renda) e decadente. Problemas de sustentabilidade (com poucos investimentos para a atividade), políticas e programas sem articulação mútua, deficiência nas normas e legislação, precária difusão de informações para os indivíduos que desempenhavam a 


\section{REVISTA TAMOIOS}

atividade, mão-de-obra desqualificada, logística, infra-estrutura e alternativas de comercialização deficientes, inexistência de linhas de crédito, são exemplos das dificuldades existentes para a prática da atividade pesqueira no início desse milênio em nosso país.

Para se ter uma idéia da importância desse setor na economia mundial, segundo a Secretaria Especial de Aqüicultura e Pesca (SEAP, 2006) a atividade pesqueira movimentou no mundo cerca de US\$ 600 bilhões no ano de 2005, tal atividade possuía um mercado duas vezes maior do que o da soja, sete vezes maior do que o de carne bovina e nove vezes maior do que o de carne de frango no mesmo ano.

Entretanto, no Brasil, apesar de possuir uma potencialidade gigantesca para a prática da pesca (existência de $8.500 \mathrm{~km}$ de costa, 4,3 milhões de $\mathrm{km}^{2}$ de Zona Econômica Exclusiva, além de possuir 12\% do total da reserva de água doce do planeta), os números não são tão expressivos, pois, por exemplo, o cidadão brasileiro consumia em 2004 cerca de $8 \mathrm{~kg}$ de pescado durante o mesmo ano (SEAP, 2006), sendo que o ideal é o consumo de $12 \mathrm{~kg}$ ao ano por cada habitante, como regulamenta a FAO (Food and Agriculture Organization of the United Nations - Organização de Agricultura e Alimentos das Nações Unidas). Para se ter uma idéia, o Brasil teria a capacidade de participar do mercado mundial com cerca de 10 milhões de toneladas por ano (FAO, 2006), só que, em 2006, o país inseria-se no mercado mundial com apenas $20 \%$ desse valor. Nos dias atuais, a necessidade de haver uma profunda interação entre sociedade e Estado se apresenta de maneira imprescindível, para que as políticas básicas que visam beneficiar a população sejam cada vez mais efetivas.

Com isso, a elaboração de políticas públicas para o atendimento e beneficiamento da categoria dos pescadores deve ser tratada com extrema importância por parte das autoridades competentes, pois a referida atividade se encontrou (e ainda hoje esse quadro não sofrera mudanças drasticamente positivas) num ostracismo sócio-produtivo por muitos e muitos anos, sendo colocada sempre em segundo plano para que outras atividades da metrópole fluminense se modernizassem e, conseqüentemente, se fortalecessem. 


\section{REVISTA TAMOIOS}

As políticas públicas são ações promovidas pelo Estado a fim de garantir a sociedade os direitos básicos que a ela os competem através da constituição, como bem explicita Cristóvam (2005):

As políticas públicas podem ser entendidas como o conjunto de planos e programas de ação governamental voltados à intervenção no domínio social, por meio dos quais são traçadas as diretrizes e metas a serem fomentadas pelo Estado, sobretudo na implementação dos objetivos e direitos fundamentais dispostos na Constituição. (Cristóvam, 2005).

Porém, ao vivermos em um momento onde a política neoliberal assola 0 mundo com sua lógica individualista e com sua proposta de manutenção e difusão da propriedade privada, as ações do Estado na promoção de políticas públicas, não é caracterizado por um viés diferente, desencadeando assim, uma série de dificuldades para aqueles que necessitam ter seus direitos relembrados e assegurados para que possam, aos poucos, se inserirem (com uma maior ligeireza) no contexto atual de mundo.

É importante ressaltar que todo o processo de implementação de políticas públicas em uma determinada sociedade, irá expressar conflitos de interesses, desencadeando assim, uma série de problemas para promover tais políticas.

Podemos, portanto, conceber as políticas públicas como sendo um conjunto de ações sociais direcionados a promover mudanças com o intuito de atingir de forma direta os grupos sociais em foco, como por exemplo, os pescadores, os ambulantes, etc., a fim de assegurar e garantir os direitos constitucionais dos mesmos. Tais ações já devidamente pensadas devem ser fomentadas pelo Estado e, sobretudo, devem ser acompanhadas com clareza, tanto pelo grupo contemplado pela política em questão, quanto pela sociedade como um todo. Vale ressaltar que a participação organizada da sociedade para a reivindicação de seus direitos é extremamente importante para a aquisição dos mesmos, fortalecendo dessa forma, a presença dos movimentos sociais no cenário político nacional. 


\section{REVISTA TAMOIOS}

Sendo assim, mais do que oferecer "serviços" sociais a população, as ações públicas, articuladas com as demandas da sociedade, devem se direcionar para a construção e manutenção dos direitos sociais, sobretudo das classes menos favorecidas.

\section{Resultados Obtidos}

A criação, promovida pelo atual Governo Federal, da Secretaria Especial de Aqüicultura e Pesca (SEAP, a qual possui como seu atual ministro Altemir Gregolin), por meio da Medida Provisória o․ 103, de 1ํ de janeiro de 2003, em seu art. 1ํ, § 3, IV, tende a viabilizar a elaboração, discussão e implementação de políticas públicas que atendam as necessidades dos pescadores e, assim, promovam o desenvolvimento da atividade não somente no estado do Rio de Janeiro, mas sim em todo o país. Como podemos evidenciar a seguir:

“(...) Cabe à SEAP assessorar direta e imediatamente o Presidente da República na formulação de políticas e diretrizes para o desenvolvimento e o fomento da produção pesqueira e aqüícola $\mathrm{e}$, especialmente, promover a execução e a avaliação de medidas, programas e projetos de apoio ao desenvolvimento da pesca artesanal e industrial, bem como de ações voltadas à implantação de infraestrutura de apoio à produção e comercialização do pescado e de fomento à pesca e aqüicultura, organizar e manter 0 Registro Geral da Pesca previsto no art. 93 do Decreto-Lei no. 221, de 28 de fevereiro de 1967, normatizar e estabelecer medidas que permitam 0 aproveitamento sustentável dos recursos pesqueiros altamente migratórios e dos que estejam subexplotados ou inexplorados, bem como supervisionar, coordenar e orientar as atividades referentes às infra-estruturas de apoio à produção e circulação do pescado e das estações e postos de aqüicultura e manter, 


\section{REVISTA TAMOIOS}

em articulação com o Distrito Federal, Estados e Municípios, programas racionais de exploração da aqüicultura em águas públicas e privadas, tendo, como estrutura básica, 0 Gabinete, o Conselho Nacional de Aqüicultura e Pesca e até duas Subsecretarias." (SEAP, 2008).

A partir da criação da SEAP, foi pensada uma maneira para organizar melhor as discussões e elaborações das políticas públicas. Dessa forma, criouse o Conselho Nacional de Aqüicultura e Pesca (CONAPE), órgão colegiado de caráter consultivo, integrante da estrutura básica da Secretaria Especial de Aqüicultura e Pesca da Presidência da República. Criado pela Lei no. 10.683, de 28 de maio de 2003, tem a finalidade de propor a formulação de políticas públicas, com o intuito de promover a articulação e o debate nos diferentes níveis de governo com a sociedade civil organizada, para o desenvolvimento e a promoção das atividades da aqüicultura e pesca no território nacional, como podemos compreender melhor abaixo:

"O Conselho é composto por 54 membros mais o Secretário Especial de Aqüicultura e Pesca e representa os sujeitos sociais interessados na área da aqüicultura e pesca. 0 Conselho é paritário e tem 27 representantes de órgãos e entidades do governo e 27 representantes de entidades da sociedade civil organizada, a seguir indicados: quinze titulares de entidades e organizações dos movimentos sociais e dos trabalhadores da pesca e aqüicultura, dez titulares de entidades da área patronal e dois titulares da área acadêmica e de pesquisa." (CONAPE, 2008).

Cabe, em suma, ao CONAPE auxiliar a formulação e a implementação de políticas públicas estruturantes, de competência da Secretaria Especial de Aqüicultura e Pesca da Presidência da República, com base nos objetivos e metas estabelecidos de forma a atender o desenvolvimento e a promoção da produção pesqueira e aqüícola. De promover e estimular as atividades de infraestrutura de apoio à produção e comercialização do pescado, deve realizar, 


\section{REVISTA TAMOIOS}

também, a normatização (respeitando a legislação ambiental) de medidas que permitam o aproveitamento sustentável dos recursos pesqueiros, entre outras medidas. (CONAPE, 2008)

No âmbito da formulação de programas e projetos, o CONAPE se propõe a realizar estudos, debates e pesquisas a respeito da aplicação e dos resultados estratégicos alcançados pelos programas desenvolvidos pela SEAP; promover (em parceria com organismos governamentais e nãogovernamentais, nacionais e internacionais) a identificação de sistemas de indicadores, no sentido de estabelecer metas e procedimentos com base nesses índices a fim de monitorar a aplicação das ações relacionadas com o desenvolvimento das atividades de aqüicultura e pesca; estimular à ampliação e o aperfeiçoamento de mecanismos de participação e controle social, visando fortalecer as atividades acima citadas; promover e organizar, também, a realização (a cada dois anos) da Conferência Nacional de Aqüicultura e Pesca; propor a atualização da legislação relacionada as atividades de aqüicultura e pesca com a finalidade de estimular as mesmas, etc. (CONAPE, 2008)

Anos mais tarde, constatou-se que a estrutura inicial da SEAP já não era suficiente para representar de maneira devida os interesses e anseios dos pescadores e aqüicultores de todo o Brasil. Dessa forma, a 2o Conferência Nacional de Aqüicultura e Pesca (realizada em junho de 2009) promovida pela SEAP/PR e pelo Conselho Nacional de Desenvolvimento da Aqüicultura e Pesca (CONAPE), com o tema a "Consolidação da Política Nacional de Aqüicultura e Pesca", aprovou a proposta de centralização de todas as competências relativas ao desenvolvimento do setor em um único órgão de governo, transformando assim, a SEAP/PR no Ministério de Pesca e Aqüicultura (MPA). Portanto, com a existência de uma instituição política sólida e da nova Lei da Pesca e Aqüicultura, sancionada no mesmo dia da criação do Ministério, a elaboração de planos e políticas se daria de maneira mais organizada e eficaz, buscando, enfim, dar apoio e orientação a todos os envolvidos na atividade pesqueira. (MPA, 2010)

A partir dessas informações, pode-se averiguar que a realização de políticas públicas para a atividade pesqueira se configura respeitando, especialmente, uma ordem nacional $x$ local o que caracteriza a realização de investimentos financeiros e de medidas de caráter informacional para diversas 


\section{REVISTA TAMOIOS}

localidades, as quais possuem na pesca sua principal fonte (ou não) de dinamicidade.

Podemos considerar a idealização de políticas públicas para a pesca artesanal em nosso país como uma temática recente, pelo simples fato de que a primeira delas que se efetivou, ou que pelo menos ganhou maior notoriedade no cenário pesqueiro nacional do novo milênio, foi a que corresponde a lei do defeso. Tal lei foi publicada no Diário Oficial da União em 26 de novembro do ano de 2003 e, em seu texto o pescador possui direitos e deveres a serem cumpridos Vejamos, de maneira resumida, como se dá esse processo.

Esta lei consiste em dar ao pescador artesanal um benefício no valor de um salário mínimo mensal durante o período de preservação das espécies (a fim de que haja uma tranqüila procriação) as quais os pescadores se dediquem. Este período de preservação é estabelecido pelo IBAMA e deve ser rigorosamente respeitado, pois, caso contrário, poderá causar sérios desequilíbrios nos biomas correspondentes às espécies.

Entretanto, para o pescador usufruir desse direito, ele deve praticar suas atividades de maneira artesanal ou em regime familiar (com meios de produção próprios ou mediante contrato de parceria), deve também possuir seu cadastro atualizado no MPA a cada três anos, bem como ter inscrição de pescador no INSS e já ter iniciado sua contribuição previdenciária. O pescador também deve ser filiado a colônia que corresponde à área onde desempenha suas atividades e também não possuir nenhum outro tipo de obtenção de renda a não ser o da pesca, deve também ter se dedicado à pesca, em caráter ininterrupto, durante o período compreendido entre o defeso anterior e o em curso (TRT, 2003). Caso o pescador não atenda a nenhuma das exigências acima citadas não poderá ser contemplado pelo benefício, ou, se algumas das informações apresentadas para adquirir o benefício forem consideradas falsas, o pescador terá seu benefício automaticamente cancelado por um período de dois anos.

Outra política pública que contemplou a categoria dos pescadores, por exemplo, foi a criação de uma política previdenciária específica e detalhada para a referida categoria, onde os pescadores artesanais e os pescadores industriais foram beneficiados com o direito de usufruir de todos os bens legais de uma aposentadoria comum, vejamos. 


\section{REVISTA TAMOIOS}

Para os pescadores artesanais, "(...) bem como os respectivos cônjuges, que exerçam suas atividades em regime de economia familiar, sem empregados permanentes, contribuirão para a seguridade social mediante a aplicação de uma alíquota sobre o resultado da comercialização da produção e farão jus aos benefícios nos termos da lei." (Ministério da Previdência Social / Secretaria de Políticas de Previdência Social, 2008). Os pescadores previamente referidos são classificados e identificados, perante os termos legais, como "segurados especiais" ou que estão atrelados à prática da agricultura, pois a categoria profissional de pescador, no âmbito artesanal, não possui ainda uma legislação mais específica e direcionada a sua classe de trabalho a qual considere e avalie todos os seus direitos e deveres de cidadão contribuinte. Além disso, para que o pescador artesanal consiga garantir o direito a previdência, ele deve obter sua renda tirada, direta e unicamente, da atividade pesqueira.

Também foi possível identificar algumas políticas públicas as quais contemplam os investimentos realizados nos âmbitos da pesca e da aqüicultura. O panorama do crédito previsto para se iniciar no ano de 2008 propõe boas quantias e também algumas facilitações para a obtenção do mesmo pelos indivíduos que exercem as atividades acima referidas.

Conforme a afirmação acima, ou seja, a respeito das principais quantias de crédito destinadas a todas as Unidades da Federação, constam o PRONAF (Programa Nacional de Fortalecimento da Agricultura Familiar) disponibilizando R\$ 500 milhões/ano e o PROFROTA (Programa Nacional de Financiamento da Ampliação e Modernização da Frota Pesqueira Nacional) comportando de crédito o total de $\mathrm{R} \$ 300$ milhões/ano. (SEAP, 2008).

Vale lembrar que somente foi possível agregar o pescador a linha de crédito rural, a partir da criação de uma nova regulamentação (Resolução 3.552/08 do Conselho Monetário Nacional), ampliando assim, as opções (e as quantias) de crédito disponíveis a categoria (SEAP, 2008).

Recentemente, mais precisamente em meados de 2008, o Ministério da Pesca e Aqüicultura consolidou, em um documento, um apanhado de políticas públicas referentes a aqüicultura e a pesca artesanal idealizadas até então. Refiro-me ao plano "Mais Pesca e Aqüicultura - Plano de Desenvolvimento Sustentável: uma rede de ações para o desenvolvimento do setor", o qual 


\section{REVISTA TAMOIOS}

comporta também a discussão sobre a importância da pesca artesanal para o Brasil em termos de produção de pescado e de categoria de trabalho, a qual emprega centenas de milhares de cidadãos em nosso país.

Seu principal objetivo é gerar mais renda para os pescadores e aqüicultores que se encontram ao longo de todo território nacional, garantindo a produção de um alimento saudável para população brasileira. Suas ações visam promover ainda um aumento na produção de pescado no Brasil até o ano de 2011, melhorando as condições sociais e de trabalho dos pescadores artesanais, reestruturando a cadeia produtiva da pesca e recuperando estoques pesqueiros na costa brasileira e nas águas continentais. (MPA - Mais Pesca e Aqüicultura - Plano de Desenvolvimento Sustentável, 2008).

Sendo assim, ao longo dessa década constata-se que uma série de medidas foram aos poucos sendo tomadas a fim de auxiliar na organização da atividade pesqueira artesanal no Brasil. A criação da SEAP no início dos anos 2000 e sua reestruturação, visando a criação do MPA no final da década, são importantes passos para fortalecer e ampliar a idealização/implementação de políticas públicas para a categoria dos pescadores artesanais de nosso país.

Acredito que o desenvolvimento de políticas públicas para os pescadores artesanais da metrópole fluminense necessita de maior atenção (e planejamento) por parte do Estado brasileiro, principalmente pelo fato de que 0 estado do Rio de Janeiro se apresenta como quarta potência na produção de pescado no Brasil.

Enfim, a necessidade de uma maior aproximação entre os indivíduos gestores da sociedade e aqueles que se encontram à margem do processo de desenvolvimento produtivo/econômico, se torna imprescindível para a manutenção das técnicas, estruturas e, sobretudo, da cultura secular que se encontra opaca, não só no território da metrópole do Rio de Janeiro, mas também (e principalmente) em todo país.

\section{ReferÊncias Bibliográficas}

BARROSO, L. V. Aspectos da Atividade de Pesca na Baía de Guanabara, Rio de Janeiro. Rio de Janeiro. IBAMA / UFRJ. 2002. 
CRISTÓVAM, J. S. da S. Breves considerações sobre o conceito de políticas públicas e seu controle jurisdicional. www.jus2.com.br. Teresina, ano 9, n. 797. Set/2005.

FOUCAULT, Michel. Microfísica do poder. Rio de Janeiro. Editora RJ - Graal. 1979.

HÖFLING, E. M. Estado e Políticas (Públicas) Sociais. Cadernos CEDES.

Campinas. Vol. 21, №. 55. Nov/2001.

SANTOS, Milton. A natureza do espaço: técnica e tempo, razão e emoção. São Paulo. SCRITTA. 1996.

SEAP, Secretaria Especial de Aqüicultura e Pesca. Mais Pesca e Aqüicultura - Plano de Desenvolvimento Sustentável: uma rede de ações para o desenvolvimento do setor. SEAP, julho/2008.

SILVA, Catia Antonia da. Qualificação profissional na construção do Brasil urbano moderno: secularização e sociedade, modernização e espaço. Orientadora: Júlia Adão Bernardes, Co-orientadora: Ana Clara Torres Ribeiro. Rio de Janeiro: PPGG/UFRJ, 2002. Tese (Doutorado).

\section{Sites consultados:}

- www.senado.gov.br (consulta a Legislação Federal - Constituição)

- www.seap.gov.br (consulta aos planos e projetos para a Pesca Artesanal)

- www.seap/conape (consulta a legislação para a Pesca Artesanal)

- www.mpa.gov.br (consulta aos planos e projetos para a Pesca Artesanal) 